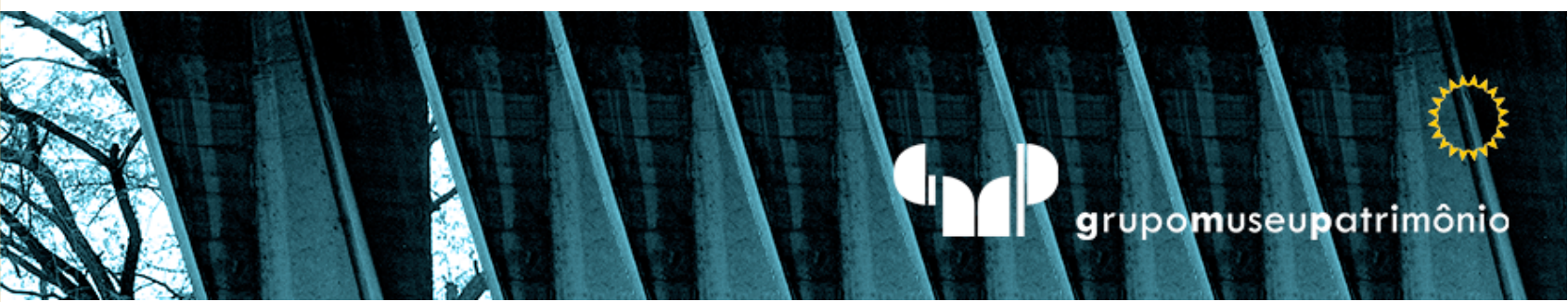

\title{
Dirigindo: emergência, fresta ou frustração?
}

\section{Driving: emergency, slot or disappointment?}

\section{Conducción: emergencia, grieta o frustración?}

\author{
Amanda Saba Ruggiero \\ Universidade de São Paulo Faculdade de Arquitetura e Urbanismo, \\ São Carlos, Brasil. amandaruggiero@usp.br
}




\title{
Resumo
}

A arte como refúgio e sentido de nossa existência, se equilibra nas demandas da sociedade contemporânea e encontra frestas de luz e oxigênio para sua sobrevivência. Apreciar obras de arte de dentro do carro, nomeada drive-thru, foi uma maneira que se anunciou na pandemia provocada pelo vírus COVID 19, como possível fruição, escape, respiro e contato com a arte. Em meio ao caótico e trágico cenário da pandemia, pergunta-se quais as reais finalidades destes eventos? Objetiva-se contato com a arte para regeneração humana ou agenciamento imediato às demandas do espetáculo e do dinheiro? O texto a seguir aproxima-se da modalidade exposição de arte drive-thru a procura de suas distintas finalidades, muitas vezes alocadas nas entrelinhas dos enunciados, a fim de ensejar reflexão acerca das exposições de arte enquanto dispositivos ou sintomas de uma dinâmica social, econômica, espacial e cultural desenhadas pela apresentação e a representação das imagens artísticas.

Palavras-Chave: Arte Contemporânea, Drive-Thru, Exposição, Pandemia.

\section{Resumen}

El arte como refugio y sentido de nuestra existencia, se equilibra en las exigencias de la sociedad contemporánea y encuentra grietas de luz y oxígeno para su supervivencia. Apreciar las obras de arte desde el interior del automóvil, Ilamado drive-thru, fue una forma que se anunció en la pandemia provocada por el virus COVID 19, como posible disfrute, escape, respiración y contacto con el arte. En medio del escenario caótico y trágico de la pandemia, uno se pregunta ¿cuáles son los verdaderos propósitos de estos eventos? ¿El contacto con el arte apunta a la regeneración humana o la agencia inmediata a las demandas del espectáculo y el dinero? El siguiente texto se acerca a la modalidad drive-in en busca de sus diferentes propósitos, a menudo distribuidos entre las líneas de los enunciados, con el fin de dar lugar a una reflexión sobre las exposiciones de arte como dispositivos o síntomas de una dimensión social, económica, espacial y cultural diseñado por la presentación y representación de imágenes artísticas.

Palabras-Clave: Arte Contemporáneo, Drive-Thru, Exposición, Pandemia.

\begin{abstract}
Refuge and sense of our existence, Art is balanced by the demands of contemporary society and finds cracks of light and oxygen for its survival. Appreciating works of art from inside the car, called drive-thru, was a way announced by the times of pandemic caused by the COVID 19 virus, as possible enjoyment, escape, breathing and contact with art. Amid the chaotic and tragic scenario of the pandemic, one wonders what are the real purposes of these events? Does approaching artworks aims at human
\end{abstract}


regeneration or agency the demands of spectacle and money? The following text approaches the drive-thru art show modality in search of its different purposes, often allocated between the lines of the statements, in order to give rise to reflection on art exhibitions as devices or symptoms of a social, economic, spatial and cultural design by the presentation and representation of artistic images.

Keywords: Contemporary Art, Drive-Thru, Exhibition, Pandemia. 


\title{
INTRODUÇÃO
}

\begin{abstract}
"Há trinta anos, o motorista podia manter um sentido de orientação no espaço. Na encruzilhada simples, uma pequena tabuleta com uma seta confirmava o que era óbvio. Sabia-se onde se estava. Quando a encruzilhada se torna um trevo, é preciso entrar à direita para dobrar à esquerda, uma contradição evocada de modo pungente na gravura de Allan D'Arcangelo. Mas o motorista não tem tempo para meditar sobre sutilezas paradoxais dentro de um labirinto sinuoso e perigoso. Ele confia nos sinais para se orientar - sinais enormes em vastos espaços, em alta velocidade." (VENTURI et al, 1977, p.34)
\end{abstract}

nvolvido por membranas, tecidos, plásticos, vidros e infinitas ligas metálicas que a tecnologia desenvolve a cada dia, nossos corpos e membros blindam-se para proteção contra as partículas virais, mãos e braços estão cada dia mais higienizados escaldados por água, sabão e álcool. Ao proteger a face, alteramos os sentidos e como se equalizam nossas percepções? Quais sinais nossos corpos se submetem além da visão cada vez mais achatada pela overdose das telas de plasma? Visitar uma exposição de arte, seja em um museu ou galeria, a céu aberto ou na cidade, para além do espetáculo, enseja imersão entre materialidades e subjetividades, telas, objetos, esculturas, cores, cheiros, sons, narrativas, emoções, reflexão ou revelações, planejadas cautelosamente pela combinação entre ambiente, 
obras, artistas, curadores, museólogos, instituições e a cidade. Em momento vivenciado por excepcionalidades, desde o isolamento dos corpos, distanciamento social, restrição de deslocamentos, questionamos se as experiências agora submetidas às restritas vivências, encontram frestas que iluminam possíveis aberturas para o novo ou somente fraturas, rupturas, incertezas pela fragmentação dos sentidos?

$\mathrm{O}$ artigo coloca em debate alguns aspectos adotados como novo formato do drive-in ou drive-thru ${ }^{1}$ de visitação e "consumo cultural", disseminado pela indústria do lazer e entretenimento durante a pandemia causada pelo vírus Covid-19. Depois do cinema drive-in, das redes fast food, consumo de alimentos, shows musicais, espetáculos de dança e teatro ${ }^{2}$, as exposições de arte têm adotado o sistema drivethru, patrocinadas por empresas, galerias, museus ou artistas. A modalidade decorre estranhamento e adiante aproximam-se os aspectos comuns e as particularidades entre as versões selecionadas.

Partindo das quatro exposições Drive-By ART (EUA), Gogh by Car (Canadá), Boijmans Ahoy drive-thru Museum (Holanda), DriveThru.Art (São Paulo) anunciadas em jornais nacionais e internacionais e redes sociais, pergunta-se quais são as finalidades desses eventos e quais experiências são esperadas? Como suposta fruição pode decorrer de visitação encapsulada por vidros e latas, obedecendo regras de tempo de permanência e sentido único para circulação? Quais aberturas se apresentam quando nos deslocamos da "fruição" para o "consumo"? O que se apresenta e representa nas mostras drive-thru em museus e exposição de arte?

\footnotetext{
${ }^{1}$ Drive-in, adjetivo usado para denominar um espaço, comércio ou serviço no qual não há necessidade de sair do automóvel. Drive-Through, substantivo utilizado para denominar um local que se pode adentrar com automóvel e utilizar seu serviço sem sair do mesmo, o termo Drive-Thru é a corruptela da palavra drive-through que significa literalmente "através do carro". Algumas mostras utilizam o termo drive-thru, pois o tempo de permanência é muito pouco em cada obra e o deslocamento do veículo se faz necessário, a mostra imersiva de Van Gogh em Toronto utiliza o termo drive-in já que o veículo entra e fica parado assim como em uma sessão de cinema.

${ }^{2}$ O jornal Folha de S. Paulo anunciou em reportagem agenda de eventos como shows, sessões de cinema, apresentação de teatro e circo, durante a pandemia. (2020, Guia Folha, p.1)
} 
A história da arte sustenta sua existência e permanência atendendo três demandas que a tornam indispensáveis na sociedade contemporânea: a formulação e produção de conhecimento, o espetáculo e o dinheiro, segundo o historiador da arte e crítico Georges Didi-Huberman (2013, p.9). Sua crítica incide sobre a disciplina história da arte, quando composta por biografias imortais e imagens enrijecidas, paralisadas perante a novas abordagens, para além de sua própria finalidade. Ao analisar imagens, Didi-Huberman sugere instrumentos de investigação pautados pelo fragmento, inexatidão, fenda aberta e o risco da incompletude determina sua postura epistemológica, de modo a olhar para as imagens e consequentemente para a história da arte, nas distintas temporalidades e incertezas, na impossibilidade do conhecimento absoluto, integral e no discurso conclusivo. A representação para DidiHuberman deve ser constantemente implodida e desconstruída, é preciso desconfiar das construções históricas para enxergar seus sintomas e dar voz às imagens que foram caladas. Das três demandas da arte, pergunta-se: como se equilibram a produção de conhecimento, a sobrevivência institucional e o mercado de arte nos eventos realizados durante a pandemia? Mantém-se a recorrência das imagens de artistas imortais, gênios e heróis? São eventos que incentivam e promovem novas abordagens e aproximações de obras e artistas? Contribuem para a produção de novos significados ou reflexão em tempos de pandemia?

$\mathrm{Na}$ tentativa de encontrar uma fresta, um respiro ou possível interação além do isolamento, o contato com a arte envolto pelo automóvel é a viabilidade encontrada para venda de valiosa relação entre público e objetos artísticos. Os organizadores das exposições realizadas nos Estados Unidos, Canadá, Holanda e Brasil anunciam finalidades diversas, desde empatia e solidariedade pela organização de artistas, até a necessidade da sobrevivência financeira das instituições e galerias para manutenção do mercado e dos sistemas de consumo da arte pelo público.

\section{O PIONEIRISMO DA IDEIA}

Contemplar do carro não é novidade, o protagonismo do automóvel como veículo condutor para observação da cidade, da paisagem e da arquitetura, está registrado desde 1972 pelos arquitetos Robert Venturi e Denise Scott Brown em Learning From 
las Vegas (VENTURI, 2003, p.34), no pioneirismo dos cinemas drive-in americanos e redes fast-food. Em tempos de pandemia gerada pelo vírus Covid-19, nos países que privilegiam a mobilidade individual por meio do automóvel, amplia-se a simbologia funcional do veículo para além do fetiche sócio econômico, ao status da cápsula sanitária, escudo protetor que permite o consumo dos produtos e bens físicos e culturais da cidade.

Nos Estados Unidos, contemplar arte pública de dentro dos carros foi notícia no jornal The New York Times desde 2009, o Drive-By Art reunia obras de artistas como Chris Burden ${ }^{3}$ entre outros, em instalações e ocupações urbanas, intervenções de outdoors e projeções, não por acaso na cidade de Los Angeles, obras exibidas em espaços públicos que não precisavam deslocar o observador do confortável assento de seus automóveis para apreciação.

No período da pandemia, a mostra Drive-By $A R T$, organizada pelo artista conceitual Warren Neidich no mês de maio nos Estados Unidos, espalhou-se pelo distrito de South Fork em Long Island, ocupando margens de estradas e rodovias integrando a comunidade de artistas locais. A mostra ocorreu em dois dias, o mapa dos locais disponíveis no website do evento indicava a posição de cada obra, com nomes e as 50 biografias resumidas dos artistas participantes (DRIVE-BY-ART, 2020). Uma ação e mobilização territorial, devido a extensão e longas distâncias, poderiam ser percorridas por carro, coerente com a morfologia urbana rarefeita dos subúrbios jardins estadunidenses. Para o organizador, a mostra foi uma tentativa de criar um senso de solidariedade com as comunidades artísticas e culturais que estavam isoladas e oferecer uma "experiência, mesmo limitada pelo distanciamento social, de interação com objetos tangíveis no mundo real". ${ }^{4}$ Neste caso, o carro era o escudo e

\footnotetext{
3 A obra de Chris Burden "Urban Light" composta por 200 luminárias antigas, réplicas "vintage" baseados em modelos dos anos 1920 e 30, localizava-se em frente ao Los Angeles County Museum of Art, e transformou-se em um exemplo proeminente de uma arte pública crescente em Los Angeles, "arte que você não precisa deixar o conforto do seu conversível para uma experiência". (NEW YORK TIMES, 2009, Arts, p.1)

${ }^{4}$ No original, texto do press release, em que organizador justifica sua iniciativa e finalidade do evento: Not only does Drive-By-Art create a sense of needed solidarity within the artistic and cultural communities now entrenched in the South Fork of Long Island, but it also offers an experience that is
} 
o meio de transporte para os longos deslocamentos e a amplitude espacial da proposta, uma escala territorial. Embora sair do seu veículo poderia ser uma atitude do público, que teria a total liberdade de fazer o percurso e observar as obras nos jardins e acostamentos nos tempos e horários livres na duração definida, além de ser obrigatório o uso das máscaras por pedestres ou ciclistas, com liberdade para se aproximar e percorrer os trabalhos expostos. O evento se apresentou como um impulso, improvisado pelas circunstâncias, feito de modo manual e caseiro, sem ambições declaradas e expectativas de vendas. Pelo material divulgado, a ação e organização de artistas, com ênfase no contato e relações de vizinhança, teve sua finalidade por ação comunitária de integração e movimentação de artistas locais (STOWE, 2020, p.1).

A mostra Gogh by Car em Toronto proporciona esta experiência de visita drive-in, porém em condições e situações muito diferentes do exemplo de Long Island. A exposição faz parte de uma itinerância programada que chegaria a Toronto em maio de 2020. A opção de permitir a visitação por automóvel não excluiu a viabilidade da experiência imersiva corporal. Quem comprou o ingresso do automóvel recebeu também entradas para fazer a visita sem o carro, a partir de julho, quando o acesso ao público, controlado, seria liberado. Marcas no chão delimitavam o posicionamento garantindo o distanciamento entre as pessoas. No texto de divulgação ${ }^{5}$ a fala dos apresentadores reforça a visita no carro como uma antecipação que não substitui a imersão corporal do passeio sem o carro. A projeção das imagens das telas de Vincent Van Gogh em tamanhos gigantescos, simultâneos, em todas as paredes e chão do ambiente, ao som de trilhas sonoras guiadas e animadas em sincronia com as imagens, é um espetáculo orquestrado que se distancia do ambiente neutro, silencioso e introspectivo de um museu ou galeria de arte tradicionais. Diferentemente do habitual, proporciona sensações auditivas, imersão em luzes e a sedução das cores e formas em mergulho corporal. Telas e

otherwise severely limited by our current social distancing practices: interacting with tangible objects in the real world. (DRIVE-BY-ART, 2020)

${ }^{5}$ No website do evento, um vídeo com áudio gravado pelos organizadores explica o recurso do automóvel como alternativa evidenciando a diferença da visita normal, garantida pela compra do ingresso. (VAN GOGH,2020). 
detalhes em escala ampliada movimentam projeções por todo ambiente em paredes, chão e teto. São estímulos envolvendo todo corpo, espetáculo que sensibiliza o grande público, crianças, jovens e adultos envoltos por meio da sincronia entre música, imagens e projeções dinâmicas e simultâneas. Não há dúvida de que a imersão difere do contato direto com tela original de Vincent Van Gogh e o clima de encanto se distancia do sofrimento e perturbações pessoais do artista, o contato visual com as telas originais exige esforço mental e imaginativo para aproximar-se dos materiais e texturas das suas telas, no geral de modestas dimensões comparada ${ }^{6}$ às gigantescas projeções. Seria necessário intervalo de tempo maior para adentrar o universo do artista, pretendido em uma hora de duração pela sessão show, cujo mérito atinge grandes audiências e públicos em massa condiz com as metas da indústria cultural do entretenimento, com distanciamento de ambiente de reflexão e introversão que muitas vezes a arte propõe.

O Museu Boijmans Van Beuningen ${ }^{7}$ de Roterdã inaugurou a exposição Boijmans Ahoy drive-thru Museum, entre os dias 1 a 23 de agosto, com cerca de 50 trabalhos da coleção do museu e outros encomendados. Uma complexa operação de adaptação e recriação das obras em um galpão do próprio museu, em suportes ampliados para que os visitantes, em seus veículos e em quantidade, pudessem ter contato com a coleção do museu. A necessidade de abrir o acervo de algum modo ao público é justificada nas palavras da organização "pelo papel que a arte pode oferecer desde certo conforto e auxiliar o encontro de alguma perspectiva, como pode também demonstrar a natureza volátil e instável da existência humana". ${ }^{8}$ Não há dúvida sobre a atualidade e a necessidade de se debater o tema, questiona-se

\footnotetext{
${ }^{6}$ Para citar alguns exemplos de telas de Vincent Van Gogh e suas dimensões: Noite estrelada 1889 (92x73cm), Auto-Retrato $1889(60,5 \times 50 \mathrm{~cm})$, Vaso com quinze girassóis $1888(92,1 \times 73 \mathrm{~cm})$.

${ }^{7}$ O Museu Boijmans Van Beuningen é um dos museus mais antigos da Holanda. Formou-se pela coleção de arte do advogado Boijmans, deixada para a cidade de Roterdã em 1849. A aquisição da coleção Van Beuningen em 1958, deu ao museu a segunda parte de seu nome. O museu abriga uma coleção de pinturas, esculturas e objetos do cotidiano, gravuras e desenhos. O museu também organiza um programa diversificado de exibições temporárias ao longo do ano. (BOIJMANS VAN BEUNINGEN, 2020, p.1)

${ }^{8}$ No texto explicativo no website do Museu, a justificativa da mostra é acompanhada por um vídeo com os bastidores da mostra, equipe e o empenho para a grandiosa produção. No original:

"Art can offer us comfort and help us to put things into perspective, and it can also show us the unpredi ctable and fickle nature of human existence". (BOIJMANS VAN BEUNINGEN, 2020, p .1)
} 
porém o pouco tempo de formulação, cujo olhar para o acervo é apropriado mas exige pesquisa, reflexão e tempo de introspecção, situação que aparenta discurso indiretamente mercantil.

Na exposição explora-se a temática ampla da relação do homem com a natureza, num diálogo entre a coleção e obras de artistas contemporâneos selecionados pelo artista e curador Ted Noten, entre nomes conhecidos do público outros menos ${ }^{9}$. Com objetivo de abordar a tensão entre as forças da natureza e a humanidade, o museu exige dos visitantes o uso do carro elétrico, e caso este não tenha o seu próprio pode alugar de um representante local e um dos patrocinadores do evento, Breeman BMW \& MINI, com direito a um breve treinamento para dirigir antes de adentrar o espaço expositivo. A arte e a cultura servem de apoio para que a marca associe sua imagem ao museu, a temática ambiental e a energia limpa, além dos valores à produção artística, ao patrimônio humano e natural, associa-se a urgência do momento atual em catástrofes climáticas, pandemia e genocídio de minorias e etnias mundo afora. O visitante pode fazer o tour sem o automóvel, em um percurso paralelo aos carros. Ampliar as imagens em formato outdoor como nas publicidades e propagandas disseminadas em estádios e grandes eventos é a estratégia anunciada para atrair o grande público, o tempo de preparo e execução segue a lógica do momento elaborado em 4 semanas, enquanto muitas exposições programadas por museus, com catálogos e montagens internacionais levam em torno de 3 anos do planejamento até sua inauguração.

O mesmo museu acaba de inaugurar uma nova sede chamada Depot, com projeto arrojado do escritório holandês MVRDV, em que a reserva técnica, local usado para acomodar a coleção do museu, está armazenada em espaço acessível ao público. Iniciativa pioneira, de um lado valoriza a coleção e possibilita uma espécie de museu depósito, com toda infra-estrutura dos museus tradicionais, em espaço interno

\footnotetext{
${ }^{9}$ Os artistas participantes que estão na coleção permanente do museu e selecionados são: Ted Noten, Oskar Kokoschka, Bas Jan Ader, Melanie Smith, Paul McCarthy, Bruce Nauman, Ugo Rondino ne, Cyprien Gaillard, Joep van Lieshout, Wieki Somers and Jim Shaw, and installations by Bas Princen, $\mathrm{Tr}$ enton Doyle Hancock, Anselm Kiefer, Olaf Nicolai and Marijke van Warmerdam.
} 
organizado por grandes vitrines com rotação temporária das obras exibidas e visitas guiadas. No edifício de fachada inteiramente espelhada e forma circular, abriga no seu último andar um mirante para a cidade com serviço de restaurante. De um lado o museu promove e vincula ações de seu acervo ao espetáculo contemporâneo, se valendo de atratores de público com inovações em sua infraestrutura e espaços expositivos. A ação da visita drive-thru corrobora neste sentido, ao manter o público próximo e dentro do museu, não importa como, a pé ou de carro. De um lado aproxima discurso e proposta temática aos interesses e patrocinadores.

\section{O Drive-Thru em SÃo PaUlo}

Em São Paulo, o evento DriveThru.Art inaugurou a modalidade no Brasil em um antigo galpão industrial na Vila Leopoldina, organizado pelo galerista e curador Luis Maluf em parceria com os donos do local chamado ARCA. O espaço recebeu painéis, fotos e vídeos de 18 artistas jovens representados pela galeria, justificado por reunir temas sociais atuais diversos como representatividade de mulheres negras, a questão indígena, gênero e a preservação do meio ambiente. Segundo o curador, ao "trazer as ruas da cidade para um galpão monumental", explica na página oficial do evento, ele "oferece um presente para a cidade". (MALUF, 2020, p.1). Neste caso, o acesso é permitido por meio de reserva e pagamento de entrada, e assim fica a questão: qual tipo de "presente" para a cidade seria? Embora no texto curatorial haja uma tentativa em resgatar o "poder social da arte", e sua finalidade que "nos torna humanos" (MALUF, 2020, p.1), parece que o resultado da proposta não representou grandes emoções ao público que visitou e relatou sua experiência. Na Vila Leopoldina a única possibilidade da visita à mostra seria por meio do automóvel próprio ou do evento (sem a exigência de um veículo "verde", ou elétrico como na Holanda). Se o propósito da exposição é o resgate do poder social da arte, em que medida há alguma ação engendrada para acionar tal "poder"? Estar em frente a obra ou passar por ela de dentro do carro, bastaria? Quais razões para justificar emergência em passar por obras de artistas em espaço e tempo controlados? O que dizem as empenas da cidade cobertas por intervenções de artistas ao motorista ou pedestre 
que as estruturas da versão Drive-thru não comunicam? Seria um "condomínio fechado" das livres e espontâneas manifestações públicas?

Outro ponto diverso das demais exposições, em São Paulo optou-se pelo formato padronizado das telas em tamanhos iguais, cerca de $10 \mathrm{~m}$ de largura, próxima às dimensões de um outdoor, estavam dispostos no local, com pé direto de 16 metros, enfileirados acompanhando a modulação das colunas do galpão. Indagamos a escolha do formato homogêneo e padronizado, em que pese a justificativa oficial, o tempo reduzido de elaboração e organização, seriam artistas selecionados exclusivamente representados pela galeria que promove o evento? Aos artistas, a encomenda formatada em curto prazo de tempo seria condizente com pesquisas e processos próprios? Ou necessidade em responder a demanda autoritária de mercado? Ao se valer de desenho modulado excessivamente ortogonal e seriado, em imagens coloridas e pulsantes, porém distante da intenção de nos humanizar, aproximam o público ou mais se parece com um "estranho depósito de outdoors", como definido pela jornalista em relato sobre visitação (BALBI, 2020, p .1).

Aspecto comum entre todas as mostras é a corrida contra o tempo, contradizendo a ideia de uma desaceleração da vida gerada pela pandemia, os eventos contabilizam tempos recordes de 3 semanas desde a concepção, produção e montagem, além daquele permitido para permanência ante cada obra. O pouco tempo de elaboração é o motivo justificado pelos organizadores de São Paulo para padronizar os formatos das imagens, o que não ocorreu com o museu Holandês, preservadas as particularidades de cada caso, lá uma instituição museal e aqui uma galeria, as três semanas de trabalho e o local permitiram uma dinâmica espacial diversa, com obras em diferentes formatos, esculturas, telas e instalações, em materiais e disposição muito mais variada e dinâmica, capaz de atrair mais do que a monótona e homogênea versão do pátio paulistano. Em ambos os casos, os carros têm obrigatoriamente que percorrer em um sentido único, com tempo cronometrado para cada parada. Neste sentido a experiência se aproxima da frustração: "O fordismo da coisa, com o perdão do trocadilho, acaba frustrando quem anda saudoso de um museu". (BALBI, 2020, p.1) 
Sobre a mostra de SP, em nenhum momento os curadores e organizadores fazem referência ao contato do corpo e com o espaço. A mostra e o suporte foram elaborados para a visão do automóvel, e isso parece não interferir na percepção do público. Nos demais casos analisados anteriormente, em todas as situações os curadores admitem a perda da percepção das relações entre obra, corpo e espaço, e de alguma forma sinalizam alternativas. Ou seja, o veículo é uma opção e não uma condição. Nestes casos, o carro é a proteção, embora o tom publicitário anunciado como uma nova forma de consumir arte, explique determinada aproximação entre fruir e consumir. Outro aspecto a notar nos textos das exposições é a recorrência dos organizadores que "presenteiam" a população com seus gestos generosos e "humanos". Retomamos a reflexão de Didi-Huberman sobre as relações entre artista e mecenas, a devoção de um e a onipotência e gesto generoso do comprador/patrocinador.

Se de um lado assistimos à tentativa de trazer manifestações de rua para um galpão fechado de acesso controlado, por outro assistimos a movimentos opostos, de modo a ampliar a escala de intervenção na cidade e defender o papel social da arte de rua como os grafites e murais. Das mensagens e imagens dos muralistas mexicanos aos muros da cidade de Filadélfia nos EUA, passando pelos murais figurativos e abstratos da arquitetura moderna, em painéis internos e externos, em grandes empenas, 0 painel público, o desenho em grandes dimensões e o grafite são da ordem da apreciação da escala urbana e pública.

O festival Na Lata, recentemente anunciado, reúne 15 artistas na região do Largo da Batata, no bairro de Pinheiros, em São Paulo, para criar um grande museu a céu aberto (VIEIRA, 2020, p. 1). Muitos apreciam as obras do carro, e muitos estão caminhando pelo bairro, um drive-thru corriqueiro inserido no cotidiano dinâmico na urbanidade. Neste caso, o circuito é livre, sem sentido único estabelecido e nem tempo cronometrado para apreciação. O controle é do indivíduo e do seu aprisionamento temporal, o tempo do semáforo vermelho, da parada obrigatória do ponto de ônibus, de um devaneio ao olhar para cima. As empenas são observadas de todos os ângulos, podem emocionar ou não, mas são públicas, livres e democráticas. 
Olhar para estes eventos à luz das instâncias que promovem arte contemporânea, a pesquisa e produção de conhecimento parece a mais comprometida, devido ao curto tempo de pesquisa e elaboração, configurando evento mais voltado ao "consumo" do que a fruição, embora sinalize o esforço do museu holandês em alinhar tema a coleção selecionada. Da mostra estadunidense, destaca o movimento comunitário e o contato com objetos reais e tangíveis. Das projeções da mostra imersiva Van Gogh, a presença corporal do indivíduo, como condicionante de fruição é ressaltada, ou seja, aponta que o invólucro do automóvel é alternativo e reduz a vivência almejada pela mostra, declaradamente temporário para adiantar o acesso do público e a arrecadação de recursos por meio da venda de ingressos a exposição. No caso da Holanda o discurso da curadoria se alinha ao modo espetacular de envolver carros elétricos (merchandise) e um show com objetos e adaptações em espaços amplo, permite o automóvel como uma bandeira atrativa da novidade pela proteção e uso de veículos elétricos (limpos), mas não dispensa o passeio e fruição do pedestre. Em São Paulo a instalação padroniza obras criadas para o evento que não destaca um tema ou eixo curatorial, inclui jovens artistas em linguagens contemporâneas diversas, mas engessa em espaço industrial o despojamento das imagens e padronizando dimensões e suporte das imagens. Na mesma cidade, iniciativas integradas à malha urbana exploram grafites e murais, feitos por jovens artistas em empenas de edifícios, ampliando a visibilidade para o automóvel e pedestre, em tempos livres de apreciação condicionadas pelos fluxos urbanos.

\section{CONSIDERAÇÕES}

A observação da cidade pelo automóvel é tarefa rotineira para aqueles que habitam cidades cujos meios de transporte coletivo são precários e o privilégio é dado ao automóvel, mesmo em relação a mobilidade do pedestre e do ciclista. 0 automóvel além da sua função mobilidade deflagra status e condição social, e agora durante a pandemia reveste-se de outra roupagem, aderindo a função de cápsula sanitária escudo protetor dos males e vírus entranhados na atmosfera urbana. Enquanto o confinamento escancara disparidades e abismos socioeconômicos entre a população, determina também a urgência e necessidade 
de espaços urbanos e públicos para receber de forma digna os habitantes da cidade e proporcionar hábitos rotineiros como caminhar, estar e contemplar a vida a céu aberto. Ao propor ações em espaços públicos e urbanos abertos a arte parece muito mais alinhada ao momento e seu papel contestador, contemplativo e transformador, do que o adestramento de manifestações em espaços enclausurados em dimensões e escalas vultuosas para maravilhar o público dentro de suas cápsulas. Nos Estados Unidos a mostra Drive-By ART se aproxima das relações humanas de vizinhança e o automóvel é o meio para circular, devido a escala das distâncias dos subúrbios americanos desde sua concepção. Nas iniciativas do evento Gogh by Car (Canadá), e do Boijmans Ahoy drive-thru Museum (Holanda), o automóvel é uma opção que não exclui o andar e o percorrer com suas próprias pernas, enquanto DriveThru.Art (São Paulo) oferece unicamente o carro em espaço de grandes dimensões, que poderia sim contemplar o caminhar, mais se aproximando de uma estratégia de marketing e novidade em tempos de pandemia. No caso de São Paulo, um presente para a cidade estaria muito mais coerente com iniciativas que pudessem repensar os espaços públicos urbanos, por meio das livres manifestações artísticas, do que um espaço privado, controlado e uniformizado por telas em grandes dimensões. Observamos em determinados discursos e propósitos dos organizadores e curadores distância da realidade e ações propostas. Se de um lado observam-se manifestações e ações que aproximam e articulam vizinhanças em ações comunitárias, por outro o apelo comercial pela novidade e pelo consumo sobrepõe qualquer dimensão emancipatória ou transformadora das manifestações artísticas. No tripé que sustenta e ordena o sistema da arte contemporânea, parece claro o desequilíbrio manifesto em mostras que se dedicam exclusivamente ao mercado e promoção do consumo, mascarados por temas atuais, polêmicos e relevantes para o debate social, sem necessariamente promover reflexões ou até mesmo incentivar a produção do conhecimento. 


\section{BIBLIOGRAFIA CITADA}

DIDI-HUBERMAN, Georges. Diante da Imagem. São Paulo: Ed. 34; 2013.

VASARI, G. TORRENTINO, L. et al. (ed.). Vidas dos artistas. São Paulo: WMF Martins Fontes; 2011.Título original: Le Vite de' più eccellenti architetti, pittori, et scultori italiani, da Cimabue, insino a' tempi nostri.

VENTURI, R. BROWN, D. S. e IZENOUR, S. Aprendendo com Las Vegas. São Paulo: Cosac Naify; 2003.

\section{Fontes eletrônicas e sites}

BALBI, Clara. Mostra de arte exclusiva para carros é boa pedida para famílias entediadas. Folha de S. Paulo. Ilustrada. 21 jul.2020. Disponível em: https://www1.folha.uol.com.br/ilustrada/2020/07/mostra-de-arte-exclusiva-paracarros-e-boa-pedida-para-familias-entediadas.shtml . Acesso em: 11 ago. 2020.

BOIJMANS VAN BEUNINGEN Art Museum. Website Oficial do museu. Roterdã, Holanda. Disponível em: https://www.boijmans.nl/en/exhibitions/boijmansahoy-drive-thru-museum. Acesso em: 10 out. 2020.

DICIONÁRIO, Cambridge. Dicionário online. Disponível em: https://dictionary.cambridge.org. Acesso em: 15 ago. 2020.

FOLHA DE S. PAULO. Na Vila Leopoldina, exposição aposta no formato drive-thru. 16 jul. 2020. Disponível em: https://guia.folha.uol.com.br/passeios/2020/07/navila-leopoldina-exposicao-aposta-no-formato-drive-thru.shtml. Acesso em: 10 ago. 2020.

MALUF, Luis. Arte em circuito vida em movimento. 2020. Disponível em: https://www.drivethru.art/exposicao. Acesso em: 10 ago. 2020.

MANNING, James. A drive-in Van Gogh exhibition is opening in Canada. Gawp at immersive digital sunflowers from the safety of your car. Time out. Disponivel em: https://www.timeout.com/news/a-drive-in-van-gogh-exhibition-isopening-in-canada-051420. Acesso em: 11 ago. 2020.

NEW YORK TIMES, Chris Burden. 05 maio 2009. Disponível em:https://www.nytimes.com/slideshow/2009/05/03/arts/20090503-LAARTslideshow_index.html?searchResult Position=3

STOWE, Stacey. Mostra de arte para carros transforma gramados e garagens em galerias 'Como mostrar empatia e solidariedade nessa nova era à qual falta solidariedade emocional?'. New York Times. 1 jun. 2020 Disponível em: https://www.nytimes.com/2020/05/11/arts/design/drive-by-art-longisland.html. Acesso em: 11 ago. 2020.

VIEIRA, Bárbara Muniz. São Paulo pretende criar maior museu brasileiro de grafite a céu aberto no Largo da Batata.15 artistas nacionais e internacionais estão 
criando simultaneamente 12 obras de 1a edição do NaLata Festival Internacional de Arte Urbana. G1 São Paulo. 09 ago. 2020. Disponível em: https://g1.globo.com/sp/sao-paulo/noticia/2020/08/09/sao-paulo-pretendecriar-maior-museu-brasileiro-de-grafite-a-ceu-aberto-no-largo-dabatata.ghtml. Acesso em: 15 ago. 2020.

WEST, Tanner. A Rotterdam Art Museum is launching a Drive-Thru Art exhibition with works by Bas Jan Ader, Paul McCarthy, and others. Artnetnews. 17 jul.2020. Disponivel em: https://news.artnet.com/art-world/drive-thru-exhibitionnetherlands-1895598. Acesso em: 12 ago.2020.

\section{Sites Eventos e locais citados}

ARCA. Website do local. São Paulo, 2020. Disponível em: http://arcaspaces.com/galeria/. Acesso em: 10 out. 2020.

DRIVE-BY ART. Catálogo Exposição. 2020. Disponível em: https://www.drive-byart.org/wp-content/uploads/2020/05/Press-Release-Drive-By-Art.pdf. Acesso em: 10 out. 2020

DRIVE - THRU ART. Website oficial do evento. Disponível em: https://www.drivethru.art/. Acesso em: 10 out. 2020.

VAN GOGH, V. Website da exposição 2020. Disponível em: https://vangoghexhibit.ca/its-safe-to-gogh/. Acesso em: 10 out. 2020. 